\title{
RESEÑA. ACERCÁNDONOS A NUESTRO ENTORNO DESDE LOS LIBROS DE NO FICCIÓN
}

\author{
REVIEW. APPROACHING OUR ENVIRONMENT FROM NON-FICTION
}

\author{
Carmen Romero Claudio \\ Universidad de Cádiz \\ https://orcid.org/0000-0002-2813-9579 \\ carmen.romeroclaudio@gmail.com
}

Recibido: 18 /03 /2020 Revisado: 19/03/2020 Aceptado: 30/03/2020

Autor: Yuval Zomer

Editorial: Juventud: Barcelona

Año: 2016,2017,2018,2019
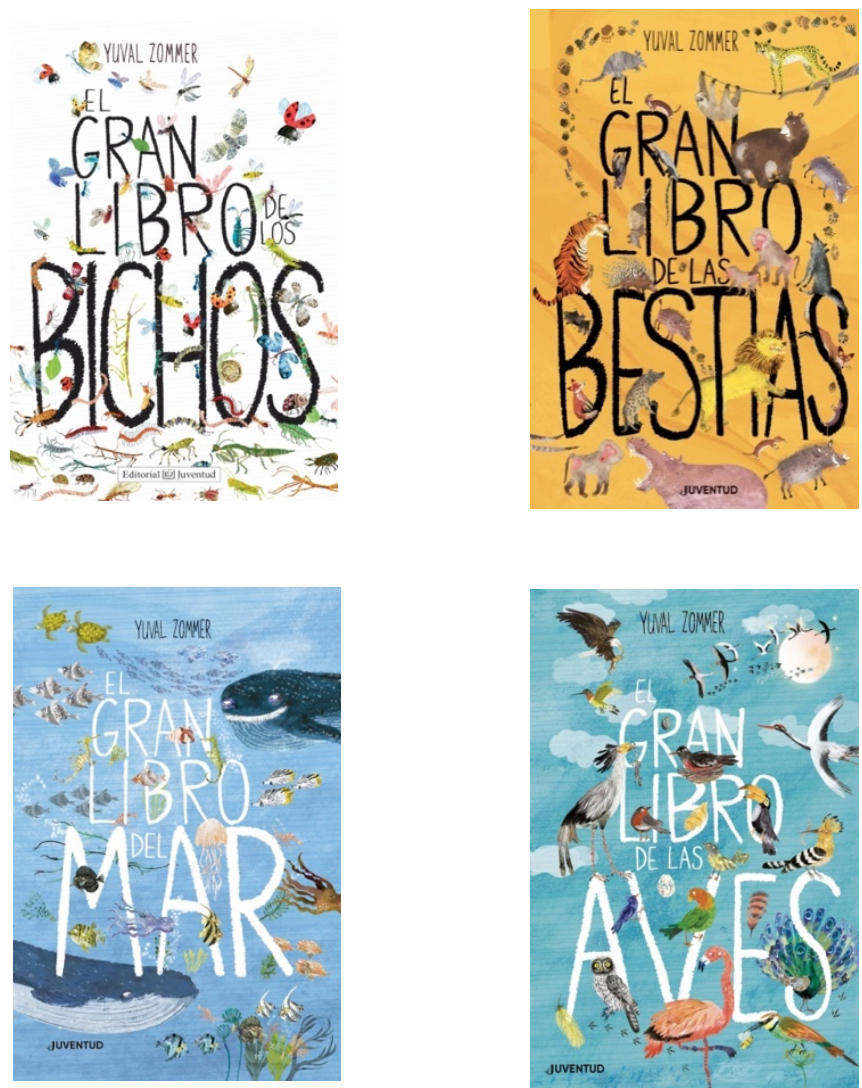

Cómo citar este artículo: Romero Claudio, C. (2020). Reseña. Acercándonos a nuestro entorno desde los libros de no ficción. Hachetetepé. Revista cientifica en Educación y Comunicación, (20), 112-114.doi: http://doi.org/10.25267/Hachetetepe.2020.i20.15

Hoy en día los libros ilustrados de no ficción están invadiendo las estanterías de las bibliotecas y librerías. Es innegable el gusto editorial por este tipo de publicaciones también denominadas libros informativos que nos ofrecen la oportunidad de convertir la lectura en un momento donde texto e imagen confluyen para el conocimiento, comprensión y descubrimiento del mundo a través de ilustraciones llamativas, llenas de color y juego, apelando al interés de los más jóvenes. Es el caso de los libros del escritor 
e ilustrador Yuval Zommer, los cuales abordan desde la curiosidad y la originalidad el mundo de la naturaleza con la colección de "El gran libro de...", en palabras del autor "intentando mirar el mundo desde la perspectiva de un niño" (su twitter @yuvalzommer).

Los cuatro títulos que presentamos en esta reseña se diferencian por sus núcleos temáticos, todos ellos relacionados con el entorno del niño y el medio ambiente (bichos, mamíferos, peces y la flora que los rodea); sin embargo, mantienen en su gran formato de tapa dura una estructura común en la que caben desde las preguntas más repetidas entre los pequeños lectores hasta las respuestas con los hechos más fascinantes y juegos donde se combinan el texto y la imagen con diferentes propósitos: entretener y divertir buscando diferentes animales a través de sus páginas; pero también concienciar sobre el medio ambiente mediante y cómo relacionarnos con la fauna y flora de manera respetuosa y ecológica; incluyéndose en todos ellos un glosario "para hablar como un experto" y las soluciones a los juegos propuestos a lo largo del libro.

En el primero, El gran libro de los bichos, los lectores se pueden adentrar en el mundo de los insectos y reptiles como arañas, gusanos, mariposas o abejas. En cada página, dedicada a un tipo de insecto, aprenderán trucos para convertirse en exploradores y observadores de su entorno. Además, tendrán la oportunidad de conocer más sobre ellos con datos contrastados que van más allá de lo anecdótico, yendo de la información más genérica a la más minuciosa.

El gran libro de las bestias da respuestas a preguntas como ¿por qué los lobos aúllan a la luna? ¿Es verdad que la hiena se ríe? o ¿Por qué les gusta tanto el barro a los hipopótamos? Entre el texto y la ilustración encontramos un libro con carácter enciclopédico en el que el aprendizaje se basa en una experiencia por descubrimiento para el lector, centrada en los animales salvajes de todo el mundo -de diferentes épocas como la Edad de Hielo-, sus diversas formas de vida, dónde encontrarlos alrededor del planeta en libertad y cómo protegerlas de la extinción.

Con El gran libro del mar quien abre sus páginas descubre todo tipo de curiosidades y juegos sobre las criaturas marinas: desde los pingüinos hasta el atún o las tortugas marinas y las ballenas. Además, servirá como guía para conocer nuevas especies y las diferencias entre ellas, como las aletas o las branquias que diferencian a unos de otros. ¿Alguna vez te has preguntado a qué profundidad vive cada especie? Sus datos contrastados son el mejor anzuelo para motivar el interés en todas las edades.

Este último año se publicó El gran libro de las aves, con el que los lectores se introducirán en el mundo de las aves que pueblan la tierra por todo el mundo. De nuevo, como en los libros anteriores de esta colección, se plantean preguntas que llegan a despertar la curiosidad tanto de jóvenes como de mayores, ya que se proponen juegos en los que las ilustraciones cobran una vital relevancia. Así, las respuestas a preguntas aparentemente simples llevarán al lector a conocer la vida de los animales plumíferos de todos los tamaños y colores por todo el mundo.

En definitiva, esta colección de libros ilustrados de no ficción propone un nuevo modelo de aprendizaje, basados en fomentar la curiosidad y el descubrimiento de nuevos mundos, a través de los libros informativos en un gran formato que se prestan a una lectura compartida, pues su contenido y su lectura fácil invita a la búsqueda de más información mas allá de sus páginas -utilizando por ejemplo soportes digitales para conocer más-. Además, pese a que puede dirigirse a un público infantil, lo podrán disfrutar todo tipo de lectores, por lo que anima a leerse entre iguales, con sus maestros y profesores, en casa con la familia... y desarrollarse a partir de ellos otras actividades con las que conocer y 
comprender el mundo que rodea a los lectores, como construir un comedero de pájaros, crear una guía propia de animales, desarrollar ideas para consumir menos recursos y ser respetuosos con la naturaleza... La mediación por parte de familia y educadores en este tipo de libros es esencial para que los lectores noveles puedan disfrutar y sacar el máximo partido a este tipo de textos y formar nuevos lectores en una sociedad en la que la imagen y el texto van unidos de la mano de estos grandes libros...

Zomer, Y. (2016). El gran libro de los bichos. Barcelona: Editorial juventud Zomer, Y. (2017). El gran libro de las bestias. Barcelona: Editorial juventud. Zomer, Y. (2018). El gran libro del mar. Barcelona: Editorial juventud. Zomer, Y. (2019). El gran libro de las aves. Barcelona: Editorial juventud. 